\title{
Prevalence and management of elevated intraocular pressure in patients with Graves' orbitopathy
}

\author{
Rachel Kalmann, Maarten Ph Mourits
}

\begin{abstract}
Aims-To investigate the prevalence and to discuss the necessity of treating elevated intraocular pressures (IOP) in patients with Graves' orbitopathy (GO). In addition, to study the effects of orbital decompression and extraocular muscle surgery on IOP.

Methods-The records of consecutive patients with GO referred in a 5 year period were studied and those selected, in which glaucoma medication had been prescribed, or a diagnosis of primary open angle glaucoma (POAG) or of ocular hypertension ( $\geqslant 22 \mathrm{~mm} \mathbf{H g}$ ) (OH) had been made. The necessity of treating these patients with glaucoma medication was questioned and the effects of corticosteroids, orbital decompression, and extraocular muscle surgery on the IOP were evaluated.
\end{abstract}

Results-Of 482 patients with GO, 23 $(4.8 \%)$ met the inclusion criteria. Four patients $(0.8 \%)$ had POAG, four had elevated IOPs and visual field defects consistent with dysthyroid optic neuropathy, and $15(3.1 \%)$ had only elevated IOPs. Five patients with $\mathrm{OH}$ showed a permanent drop of IOP after orbital decompression, two had a marked decrease of their IOP after recession of the inferior rectus muscle.

Conclusions-POAG has the same prevalence in the general Dutch population as in the GO subgroup. The combination of elevated IOPs and visual field defects in GO patients may be attributed to other mechanisms than obstructed aqueous outflow in the trabecular meshwork and should be treated accordingly. Orbital decompression and extraocular muscle surgery may lower the IOP in patients with GO.

(Br F Ophthalmol 1998;82:754-757)

Utrecht, Donders

Institute of

Ophthalmology,

University Hospital

Utrecht, Netherlands

R Kalmann

$\mathrm{M} \mathrm{Ph}$ Mourits

Correspondence to: Rachel Kalmann, MD,

Donders Institute of

Ophthalmology, University

Hospital of Utrecht,

Heidelberglaan 100, 3584

CX, Utrecht, Netherlands.

Accepted for publication 29 January 1998 cases. ${ }^{1}$ POAG is diagnosed through the clas triad of elevated IOP, with open angle of the anterior chamber, glaucomatous cupping of the optic disc, and characteristic visual field loss. ${ }^{2}$ Risk factors in the development of glaucomatous optic nerve damage are the amount of elevation of the IOP, increasing age, a family history of glaucoma, and black race. ${ }^{3-5}$ Patients with elevated IOP, but normal visual fields and cup/disc ratios, are classified as having ocular hypertension $(\mathrm{OH})$. This group of patients is usually managed by observation alone. In cases at high risks, treatment is considered after carefully weighing the advantages and disadvantages of the therapy. Since POAG is a chronic and progressive disease the diagnosis has serious implications for the patient.

In patients with Graves' orbitopathy, elevated IOP in upgaze is a common finding (65-100\%) and is explained by a tight inferior rectus muscle that blocks the episcleral aqueous outflow and orbital congestion. ${ }^{6-11}$ The IOP is mostly measured using applanation tonometry, for which the eyes are held in mild upgaze. ${ }^{12}$ In a number of patients with Graves' orbitopathy, elevated pressures are found; they are thus easily considered to be patients with $\mathrm{OH}$ and treated as such.

The aims of this retrospective study were to investigate the prevalence of POAG and $\mathrm{OH}$ and to establish the necessity of treating elevated IOP in patients with Graves' orbitopathy. As increased orbital pressure ${ }^{13}$ and tight extraocular muscles (both found in Graves' orbitopathy) decrease the episcleral aqueous outflow, resulting in an increase of IOP, the effects of orbital decompression and recession of the extraocular muscles were studied.

\section{Patients and methods}

We retrospectively studied the records of 482 consecutive patients with Graves' orbitopathy referred to the Donders Institute of Ophthalmology during the period January 1992January 1997. Included in this study were patients with a diagnosis of Graves' orbitopathy (based on the clinical picture, a characteristic computed tomograph scan, and supported by immunological and/or endocrinological findings) and who met one of the following criteria: the use of glaucoma medication at referral, repeated elevated IOPs ( $\geqslant 22 \mathrm{~mm} \mathrm{Hg}$ ) measured by applanation tonometry in the standard position, glaucomatous or dysthyroid optic neuropathy (DON) visual field defects and/or glaucomatous optic disc cupping. In those patients who fulfilled the inclusion criteria, age at referral, sex, and race were recorded as well as the family history for glaucoma. Depth of 
Table 1 Patients with a Graves'orbitopathy and primary open angle glaucoma $(n=4)$

\begin{tabular}{|c|c|c|c|c|c|c|}
\hline $\begin{array}{l}\text { Patient no } \\
\text { (age (years)) }\end{array}$ & Sex & $\begin{array}{l}I O P(\text { mm } H g), R / L \\
\text { medication }\end{array}$ & Optic disc & Visual fields & $\begin{array}{l}\text { Anterior } \\
\text { chamber }\end{array}$ & Comment \\
\hline $1(74)$ & $\mathrm{F}$ & $\begin{array}{l}\text { 13/25 timolol, } \\
\text { pilocarpine right eye }\end{array}$ & $\begin{array}{l}\text { Right eye: glaucomatous } \\
\text { C/D ratio } \\
\text { Left eye: normal }\end{array}$ & $\begin{array}{l}\text { Right eye: central rest } \\
\text { Left eye: normal }\end{array}$ & deep & \\
\hline $2(54)$ & $\mathrm{F}$ & $\begin{array}{l}\text { 26/26, timolol, } \\
\text { dipivedrin both eyes }\end{array}$ & $\begin{array}{l}\text { Both eyes: glaucomatous } \\
\mathrm{C} / \mathrm{D} \text { ratio }\end{array}$ & $\begin{array}{l}\text { Both eyes: nerve fibre } \\
\text { bundle defects }\end{array}$ & deep & \multirow{3}{*}{$\begin{array}{l}\text { pseudoexfoliation, } \\
\text { trabeculectomy both } \\
\text { eyes in } 1996\end{array}$} \\
\hline $3(64)$ & $\mathrm{F}$ & $\begin{array}{l}19 / 27 \text {, betaxolol both } \\
\text { eyes }\end{array}$ & $\begin{array}{l}\text { Both eyes: glaucomatous } \\
\text { C/D ratio }\end{array}$ & $\begin{array}{l}\text { Both eyes: } \\
\text { centrocaecal scotoma }\end{array}$ & deep & \\
\hline $4(48)$ & $\mathrm{F}$ & $\begin{array}{l}21 / 22 \text {, timolol both } \\
\text { eyes }\end{array}$ & $\begin{array}{l}\text { Both eyes: glaucomatous } \\
\mathrm{C} / \mathrm{D} \text { ratio }\end{array}$ & $\begin{array}{l}\text { Both eyes: temporal } \\
\text { defect }\end{array}$ & deep & \\
\hline
\end{tabular}

$\mathrm{C} / \mathrm{D}=$ cup/disc.

the anterior chamber, results of gonioscopy, extent and depth of visual fields (tested with Peritest), and the response on glaucoma medication on the IOP were registered. Computed tomography (CT) scans were reevaluated and apical crowding assessed. The medical and surgical interventions and their effects on the IOP and visual fields were evaluated immediately after and 3-6 months after treatment.

\section{Results}

Out of 482 patients with Graves' orbitopathy $23(4.8 \%)$ met the inclusion criteria. There were 20 females and three males; mean age at referral was 55.0 years (range 23-77 years). All patients were white and all used glaucoma medication.

PREVALENCE OF POAG (TABLE 1)

Four patients, seven eyes $(0.83 \%)$ had POAG, with a cup/disc ratio $>0.5$, typical glaucomatous visual field defects, and pressures ranging from 16 to $27 \mathrm{~mm} \mathrm{Hg}$ with medication (patients 1-4).

EFFECTS OF MEDICAL AND SURGICAL THERAPY FOR GRAVES' ORBITOPATHY ON THE IOP (TABLE 2) Two patients had elevated IOPs, visual field defects (concentric and arcual), but normal optic discs (patients 5 and 6). Their CT scans showed apical crowding of the extraocular muscles. They were treated with steroids for DON, after which the visual fields normalised. In one of them the IOP decreased from $26 \mathrm{~mm}$ $\mathrm{Hg}$ on both sides with timolol $0.5 \%$ twice daily to $16 \mathrm{~mm} \mathrm{Hg}$ on both sides without therapy. In the other patient the IOP remained elevated.

One patient (patient 7) had IOPs of 26-28 $\mathrm{mm} \mathrm{Hg}$ with timolol $0.5 \%$ twice daily, optic disc swelling, and visual field defects (upper and lower nerve fibre bundle defects on the right side and a centrocaecal defect on the left side). The optic discs and the visual fields of this patient normalised after a three wall orbital decompression, while the IOPs showed an obvious decrease postoperatively (14-15 mm $\mathrm{Hg}$ with timolol $0.5 \%$ twice daily).

Another patient (number 8 ) who had visual field defects, but normal optic discs also showed a decrease in IOP after a three wall orbital decompression. Postoperatively her visual field defects disappeared.

Three patients with normal optic discs and normal visual fields showed a decrease of the IOP (mean decrease $4.2 \mathrm{~mm} \mathrm{Hg}$ ) after orbital decompression which lasted for at least 3 months (patients 9, 10, and 11).

Two patients demonstrated a marked decrease of IOP (mean decrease $12.2 \mathrm{~mm} \mathrm{Hg}$ ) after recession of the inferior rectus muscles (patients 12 and 13).

Table 2 Course of intraocular pressure (IOP) and visual fields in patients with elevated IOPs treated for Graves'orbitopathy (GO) with steroids, or orbital decompression, or inferior rectus muscle recession $(n=9)$

\begin{tabular}{|c|c|c|c|c|c|c|c|c|c|}
\hline $\begin{array}{l}\text { Patient no } \\
\text { (age (years)) }\end{array}$ & Sex & $\begin{array}{l}\text { IOP ( } \mathrm{mm} \mathrm{Hg} \text { ) } \\
\mathrm{R} / \text { L before } \\
\text { glaucoma therapy }\end{array}$ & $\begin{array}{l}I O P(m m H g) R / L \\
\text { before GO therapy, } \\
\text { (medication) }\end{array}$ & $\begin{array}{l}\text { Optic } \\
\text { disc }\end{array}$ & Visual fields & Therapy for $G O$ & $\begin{array}{l}\text { Indication for } \\
\text { therapy }\end{array}$ & $\begin{array}{l}I O P(\mathrm{~mm} \mathrm{Hg}) \\
R / L>3 \text { months } \\
\text { after GO therapy }\end{array}$ & $\begin{array}{l}\text { Visual fields } \\
\text { after GO } \\
\text { therapy }\end{array}$ \\
\hline $5(68)$ & $\mathrm{F}$ & $28 / 28$ & $\begin{array}{l}\text { 26/26, (timolol, } \\
\text { pilocarpine) }\end{array}$ & normal & $\begin{array}{l}\text { Both eyes: } \\
\text { concentric } \\
\text { defects }\end{array}$ & steroids IV & DON & $\begin{array}{l}\text { 23/23, timolol, } \\
\text { pilocarpine }\end{array}$ & normal \\
\hline $6(42)$ & $\mathrm{F}$ & $25 / 25$ & 21/21, (timolol) & oedema & $\begin{array}{l}\text { Both eyes: arcual } \\
\text { defects }\end{array}$ & steroids IV & DON & $15 / 16$ & normal \\
\hline $7(65)$ & $\mathrm{F}$ & $25 / 31$ & 28/26, (timolol) & oedema & $\begin{array}{l}\text { Both eyes: nerve } \\
\text { fibre bundle } \\
\text { scotoma }\end{array}$ & $\begin{array}{l}3 \text { wall orbital } \\
\text { decompression }\end{array}$ & $\mathrm{DON}$ & $14 / 15$, timolol & normal \\
\hline $8(73)$ & $\mathrm{F}$ & $27 / 27$ & $24 / 24$, (timolol) & normal & $\begin{array}{l}\text { Both eyes: } \\
\text { peripheral defects }\end{array}$ & $\begin{array}{l}3 \text { wall orbital } \\
\text { decompression }\end{array}$ & DON & $15 / 17$ & normal \\
\hline $9(42)$ & M & $25 / 28$ & 20/17, (timolol) & normal & normal & $\begin{array}{l}3 \text { wall orbital } \\
\text { decompression }\end{array}$ & rehabilitative & 14/14, timolol & normal \\
\hline $10(23)$ & $\mathrm{F}$ & $24 / 24$ & $21 / 21$, (timolol) & normal & normal & $\begin{array}{l}3 \text { wall orbital } \\
\text { decompression }\end{array}$ & rehabilitative & $17 / 17$ & normal \\
\hline $11(54)$ & $\mathrm{F}$ & $24 / 26$ & $22 / 20$, (timolol) & normal & normal & $\begin{array}{l}2 \text { wall orbital } \\
\text { decompression }\end{array}$ & rehabilitative & $18 / 16$ & normal \\
\hline $12(48)$ & $\mathrm{F}$ & $25 / 22$ & $25 / 22$, betaxolol & normal & normal & $\begin{array}{l}\text { Both eyes: } \\
\text { inferior rectus } \\
\text { muscle recession }\end{array}$ & diplopia & $14 / 14$ & normal \\
\hline $13(48)$ & $\mathrm{F}$ & $36 / 41$ & $\begin{array}{l}\text { 33/33, timolol, } \\
\text { pilocarpine }\end{array}$ & normal & normal & $\begin{array}{l}\text { Both eyes: } \\
\text { inferior rectus } \\
\text { muscle recession }\end{array}$ & high IOP & $18 / 18$, timolol & normal \\
\hline
\end{tabular}


COURSE OF IOP WITHOUT INTERVENTION

(TABLE 3)

In the remaining 10 patients (numbers 14-23), with normal optic discs and normal visual fields, who did not undergo orbital decompression or inferior rectus muscle recession and who were not treated with steroids, the IOP remained unchanged (mean $21 \mathrm{~mm} \mathrm{Hg}$, range $14-27 \mathrm{~mm} \mathrm{Hg}$ with glaucoma medication).

The mean IOP before glaucoma medication in these patients was $26.8 \mathrm{~mm} \mathrm{Hg}$, on repeated measurements (range $22-37 \mathrm{~mm} \mathrm{Hg}$ ).

CASE PRESENTATIONS

A 65 year old woman (patient 7) was referred in April 1994 because of DON and POAG. On admission the visual acuity was 0.1 on the right eye and 0.4 on the left eye. Her Hertel readings were $22 \mathrm{~mm}$ on both sides. The optic discs were slightly swollen and choroidal folds were visible. The IOP was 28 and $26 \mathrm{~mm} \mathrm{Hg}$ respectively, with timolol $0.5 \%$ twice daily. The right visual field showed upper and lower nerve fibre bundle defects, the left visual field showed a centrocaecal scotoma. The CT scan showed apical crowding. A three wall orbital decompression via a coronal approach was performed to decrease the pressure on the optic nerve. Her visual acuity increased to 0.5 on both sides, 3 months postoperatively. Hertel readings decreased to $18 \mathrm{~mm}$ on the right and 17 $\mathrm{mm}$ on the left side. Funduscopy showed no obvious abnormalities and visual field testing showed only relative scotomata on both sides. Her IOPs were 14 and $15 \mathrm{~mm} \mathrm{Hg}$ with timolol $0.5 \%$ twice daily, which was discontinued.

A 48 year old woman (patient 13) with Graves' orbitopathy was referred in November 1995 because of irritation and photophobia and a symmetrical elevation restriction as a result of Graves' orbitopathy. Her visual fields and optic discs were normal. Even with dipivefrine $0.1 \%$, timolol $0.5 \%$ twice daily, and dorzolamide $0.1 \%$ twice daily and after a laser trabeculoplasty her IOPs were still around 33 $\mathrm{mm} \mathrm{Hg}$, when measured with applanation tonometry. When we measured the IOPs with a Tonopen the same pressures were found. However, when we measured the IOPs with a Tonopen and with the patient looking slightly down, the IOP was $21 \mathrm{~mm} \mathrm{Hg}$ on both sides. Because of this finding and the symmetrically restricted elevation, a recession of the inferior rectus muscles was performed. Three weeks postoperatively the IOP was $21 \mathrm{~mm} \mathrm{Hg}$ on both sides, measured in the standard position,

Table 3 Patients with Graves'orbitopathy (GO) and elevated intraocular pressure (IOP) without intervention for $G O(n=10)$

\begin{tabular}{llllll}
\hline $\begin{array}{l}\text { Patient no } \\
\text { (age } \\
\text { (years) })\end{array}$ & Sex & $\begin{array}{l}\text { IOP }(\mathrm{mm} \mathrm{Hg}) \\
\text { before glaucoma } \\
\text { medication }\end{array}$ & $\begin{array}{l}\text { IOP }(\mathrm{mm} \mathrm{Hg}) \mathrm{R} / \text { L, glaucoma } \\
\text { medication }\end{array}$ & Optic disc & Visual fields \\
\hline $14(48)$ & $\mathrm{F}$ & $29-27$ & $20 / 20$, timolol & normal & normal \\
$15(73)$ & $\mathrm{M}$ & unknown & $24 / 24$, betaxolol & normal & normal \\
$16(44)$ & $\mathrm{F}$ & $28 / 22$ & $23 / 16$, timolol, dipivefrin & normal & normal \\
$17(53)$ & $\mathrm{F}$ & $36 / 37$ & $26 / 26$, timolol & normal & normal \\
$18(77)$ & $\mathrm{F}$ & $22 / 23$ & $14 / 14$, timolol & normal & normal \\
$19(54)$ & $\mathrm{F}$ & $24 / 24$ & $15 / 15$, timolol & normal & normal \\
$20(60)$ & $\mathrm{F}$ & $24 / 24$ & $22 / 20$, betaxolol & normal & normal \\
$21(43)$ & $\mathrm{F}$ & $26 / 23$ & $16 / 16$, timolol & normal & normal \\
$22(41)$ & $\mathrm{F}$ & $34 / 28$ & $17 / 17$, timolol & normal & normal \\
$23(69)$ & $\mathrm{M}$ & $26 / 26$ & $19 / 18$, betaxolol & normal & normal \\
\hline
\end{tabular}

with the above mentioned therapy. Three months later, the IOPs were $19 \mathrm{~mm} \mathrm{Hg}$ with timolol $0.5 \%$ only. Pressures without treatment are not known yet. She did not develop double vision and the elevation markedly improved.

\section{Discussion}

Wessely, in 1918, was the first to describe increased IOP on upgaze in patients with Graves' orbitopathy. ${ }^{6}$ Since then several other studies described the phenomenon of increased IOP on upgaze in patients with Graves' orbitopathy. ${ }^{7-11}$ All studies agree on the mechanism of the increased IOP on upgaze; inelasticity of the inferior rectus muscle as a result of fibrosis and thus the incapacity to relax causes compression on the globe when the antagonist pulls the eye upwards.

In this study concerning 482 patients with Graves' orbitopathy, 23 were found to have elevated IOPs. All were treated with glaucoma medication. Four patients turned out to have POAG. The prevalence of glaucoma in this population of patients with Graves' orbitopathy $(0.8 \%)$ corresponds to the $1.1 \%$ prevalence of the general Dutch population. ${ }^{14}$ Patient 7 (together with patients 5, 6, and 8) demonstrated the diagnostic confusion occurring in patients with Graves' orbitopathy, elevated IOPs, and visual field defects. The visual field defects disappeared completely after orbital decompression; they had been related to POAG initially, but were in fact caused by optic nerve compression due to grossly enlarged extraocular muscles. The absence of glaucomatous cupping should have been decisive.

We consider the decrease in IOP after orbital decompression, demonstrated in five patients, an important finding. The IOP is determined by the rate of aqueous humour production by the ciliary body, the resistance to aqueous outflow across the trabecular meshwork, and the level of episcleral vessel pressure. Increased orbital pressure in Graves' orbitopathy causes increased episcleral venous pressure, which subsequently causes increased IOP. Orbital decompression decreases the IOP by reducing the intraorbital pressure and thus the episcleral venous pressure. This study demonstrates that in patients with Graves' orbitopathy and elevated IOP, who will undergo orbital decompression, the postoperative IOP has to be awaited before surgical measures concerning the IOP are taken.

Two patients showed a decrease in IOP after recession of the inferior rectus muscle. In Graves' orbitopathy, the inferior rectus muscle is enlarged and fibrotic. It causes compression of the globe, which results in an increase of the episcleral venous pressure, just as elevated intraorbital pressure does. Recession of the inferior rectus muscle decreases its tension and therefore diminishes the compression on the globe. In one patient, recession of the inferior rectus muscle was performed because of diplopia, and the IOP decrease postoperatively was a secondary finding. In the other patient (case 3) symmetric recession of the inferior 
rectus muscle was primarily performed in order to decrease the IOP; a trabeculectomy could be averted.

In retrospect, 19 patients $(3.9 \%)$ had elevated IOPs with non-glaucomatous optic discs or visual fields. The prevalence of ocular hypertension in the general population older than 30 years is $1.6 \%{ }^{15}$ This difference may be caused by the fact that normally, when looking at the applanation tonometer, the eyes are in mild upgaze as demonstrated in the study of Reader, ${ }^{12}$ giving rise to elevated pressures in some patients with Graves' orbitopathy. Probably the IOP would have been normal in some of them if they would look straight ahead, or slightly down. Unfortunately, in this retrospective study, these measurements were not available. In the recent study of Peele Cockerham et $a l,{ }^{16}$ the $24 \%$ prevalence of ocular hypertension in 500 patients with Graves' orbitopathy could be partly explained by the mechanism of looking slightly upwards during applanation tonometry, as discussed above.

We firstly conclude that the diagnosis of POAG and $\mathrm{OH}$ in patients with Graves' orbitopathy should be made with special care. In prescribing glaucoma medication to these patients the same considerations should be followed as for non-Graves' patients. The IOP should be measured in standard position and in downgaze. Visual field defects of DON must not be confused with that of glaucoma. Secondly, we conclude that orbital decompression and recession of the inferior rectus muscle may reduce the IOP.
1 Char DH. Eye signs and diagnosis. In: Rootman J. Diseases of the orbit. Philadelphia: JB Lippincott 1988:241-80.

2 Hoskins HD, Kass MA. Becker Shaffer's diagnosis of glaucoma. St Louis: CV Mosby, 1982:2.

3 Perkins ES, Phelps CD. Open angle glaucoma, ocular hypertension, low tension and glaucoma. Arch Ophthalmol 1982;100:1464-8.

4 Anderson DR. The management of elevated intraocular pressure with normal optic discs and visual fields. 1 Therapeutic approach based on high-risk factors. Surv Ophthalmol 1977;21:479.

5 Sommer A, Tielsch JM, Katz J. Relationship between intraocular pressure and primary open angle glaucoma among white and black Americans: the Baltimore Eye Survey. Arch Ophthalmol 1991;109:1090-6.

6 Wessely K. Discussion of Hertel E. Weiterer Beitrag zur Lehre von Augendruck. Ber Dtsch Ophthalmol Ges 1918;41: $80-1$.

7 Braley AE. Malignant exophthalmos. Am $f$ Ophthalmol 1958;36:1286-90.

8 Lyons DE. Postural changes in IOP in dysthyroid exophthalmos. Trans Ophthalmol Soc 1971;91:799-803.

9 Gamblin GT, Harper DG, Galentine P, et al. Prevalence of increased intraocular pressure in Graves' diseaseevidence of frequent subclinical ophthalmopathy. $N$ Engl F Med 1983; 308:420-4.

10 Nardi M, Bartolomei MP, Romani A, et al. Intraocular pressure changes in secondary positions of gaze in normal subjects and in restictive ocular motility disorders. Graefes Arch Ophthalmol 1988;226:8-10.

11 Fishman DR, Benes SC. Upgaze intraocular pressure changes and strabismus in Graves' ophthalmopathy. $\mathcal{F}$ Clin Neuro-ophthalmol 1991;11:162-5.

12 Reader AL. Normal variations of intraocular pressure on vertical gaze. Ophthalmology 1982;89:1084-7.

13 Otto AJ, Mourits M Ph, Deen-van Leeuwen L. Retrobulbar pressures measured during surgical decompression of the orbit. Br f Ophthalmol 1996;80:1012-45.

14 Dielemans I, Vingerling JR, Wolfs R, et al. The prevalence of glaucoma in a population-based study in the Netherlands: the Rotterdam Study. Ophthalmology 1994;101:1851-5.

15 Armaly MF, Krueger DE, Maunder L, et al. Biostatistical analysis of the collaborative glaucoma study. Arch Ophthalmol 1980;98:2163-71

16 Peele Cockerham K, Pal Ch, Jani B, et al. The prevalence and implications of ocular hypertension and glaucoma in thyroid-associated orbitopathy. Ophthalmology 1997;104: 914-1. 